\title{
Clinical utility of serum cystatin $C$ for prediction of multi-vessel disease by coronary angiography in type 2 diabetes mellitus patients with normal renal function
}

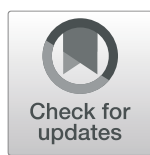

Shaoyi Wang ${ }^{1,2+}$, Qiaohui Liu ${ }^{1 \dagger}$, Fangfang Guo ${ }^{3}$, Xiaocong Zhou ${ }^{4}$, Jie Shi ${ }^{1,2}$ and Qing Xie ${ }^{3^{*}}$

\begin{abstract}
Background: The aim of this study was to evaluate whether serum cystatin $C$ could serve as a predictor of multivessel coronary artery disease identified by coronary angiography in type 2 diabetes patients with normal renal function and to suggest the cutoff point of serum cystatin $\mathrm{C}$ for predicting multivessel disease.

Methods: Serum cystatin C concentrations were measured by using particle-enhanced immunonephelometric assays before coronary angiography in 135 consecutive type 2 diabetes patients and 179 nondiabetic patients with normal renal function. Routine anthropometric and serologic data were collected. The severity of multivessel disease was assessed with the Gensini score after coronary angiography. The associations of serum cystatin $C$ with the Gensini score were investigated, and the independent risk factors associated with multivessel disease were assessed.

Results: Serum cystatin C and the Gensini score were significantly elevated in diabetes patients. Cystatin C had a positive correlation with Gensini score. A multiple logistic regression analysis demonstrated that cystatin C was independently associated with the presence of multivessel disease (the OR score is $2.21, P=0.003$ ). Based on the ROC curve, a cystatin C level of $0.865 \mathrm{mg} / \mathrm{L}$ showed $67.7 \%$ sensitivity and $76.3 \%$ specificity with an AUC of 0.748 in diabetes patients for detecting multivessel disease.

Conclusion: Serum cystatin C is significantly correlated with the presence of multivessel disease, suggesting that cystatin $\mathrm{C}$ might be utilized as a screening tool for predicting multivessel disease in type 2 diabetes mellitus patients with normal renal function.
\end{abstract}

Keywords: Cystatin C, Gensini score, Diabetes mellitus, Multivessel disease

\section{Introduction}

Type 2 diabetes mellitus is common and an important cause of morbidity and mortality. Type 2 diabetes mellitus is associated with accelerated atherosclerotic processes affecting arteries that supply major organs in the

\footnotetext{
* Correspondence: xieqingql@126.com

†Shaoyi Wang and Qiaohui Liu contributed equally to this work. ${ }^{3}$ Pharmacy Department, Qilu Hospital of Shandong University, No.107, Wen Hua Xi Road, Jinan, Shandong 250012, People's Republic of China Full list of author information is available at the end of the article
}

body. Therefore, patients with diabetes are at high risk for cardiovascular diseases, stroke and renal dysfunction $[1,2]$. A series of studies have demonstrated that multiple factors, including hyperglycaemia, fluctuating blood glucose levels, central obesity, and hyperlipidaemia, contribute to the increased risk of CAD (cardiovascular diseases) $[3,4]$. The link between hyperglycaemia and cardiovascular disease is well documented, and there is ample epidemiological evidence that hyperglycaemia is

C C The Author(s). 2020 Open Access This article is licensed under a Creative Commons Attribution 4.0 International License, which permits use, sharing, adaptation, distribution and reproduction in any medium or format, as long as you give appropriate credit to the original author(s) and the source, provide a link to the Creative Commons licence, and indicate if changes were made. The images or other third party material in this article are included in the article's Creative Commons licence, unless indicated otherwise in a credit line to the material. If material is not included in the article's Creative Commons licence and your intended use is not permitted by statutory regulation or exceeds the permitted use, you will need to obtain permission directly from the copyright holder. To view a copy of this licence, visit http://creativecommons.org/licenses/by/4.0/ The Creative Commons Public Domain Dedication waiver (http://creativecommons.org/publicdomain/zero/1.0/) applies to the data made available in this article, unless otherwise stated in a credit line to the data. 
an independent predictor of cardiovascular mortality in patients with DM (diabetes mellitus) [5].

Multivessel disease is the most fatal and frequently observed coronary artery disease in type 2 diabetes patients. Until now, no simple, noninvasive screening tool has been available. The close correlation between multivessel disease and fluctuating blood glucose levels in type 2 diabetes patients has been shown in clinical and experimental studies [6]. However, the detailed mechanisms underlying the link between multivessel disease identified by coronary angiography and type 2 diabetes mellitus remain to be elucidated. Fluctuating blood glucose levels cannot fully explain the close association.

Cystatin $\mathrm{C}$, which is less influenced by sex, age and race, has been considered a novel sensitive marker for detecting renal dysfunction [6-9], and a combined creatinine-cystatin $\mathrm{C}$ equation has been suggested for classification of the estimated glomerular filtration rate (eGFR) instead of creatinine alone [6]. A number of studies have demonstrated that cystatin $\mathrm{C}$ is closely associated with cardiovascular disease, including incident congestive heart failure [9] and carotid atherosclerosis [10], and is significantly associated with the presence and severity of asymptomatic coronary artery disease in metabolic syndrome patients with normal kidney function [11]. Moreover, the association between serum cystatin $\mathrm{C}$ and the risk of progression from normoglycaemia to prediabetes has been reported [12]. To date, the relationship between cystatin $\mathrm{C}$ and multivessel disease in diabetes mellitus patients remains unclear. Therefore, this study was conducted to explore the role of cystatin $\mathrm{C}$ in multivessel coronary artery disease in type 2 diabetes patients with normal renal function and to determine whether cystatin $\mathrm{c}$ influences multivessel coronary artery disease independent of traditional risk factors. In addition, we investigated whether cystatin $\mathrm{C}$ can serve as a biomarker to predict the presence of multivessel coronary artery disease.

\section{Methods}

\section{Study subjects}

A total of 135 type 2 diabetes patients and 179 agematched subjects without diabetes with a normal estimated glomerular filtration rate (eGFR) were enrolled in this cross-sectional study. All patients were admitted to QiLu Hospital of Shandong University (Jinan, China) and were referred for elective coronary angiography for suspected coronary artery disease by cardiologists from March 2010 to March 2012. None of the patients in this study suffered from malignancy, inflammatory disease, valvular heart disease, renal dysfunction (creatinine-based eGFR $<90 \mathrm{~mL} /$ $\mathrm{min} / 1.73 \mathrm{~m}^{2}$, serum creatinine $>133 \mu \mathrm{mol} / \mathrm{L}$ ), or hepatic dysfunction. Large doses of glucocorticoids enhance cystatin C [13]. Thyroid dysfunction also influences cystatin C levels $[14,15]$. Therefore, individuals with these factors were also excluded from this study. Written informed consent was obtained from all subjects. The study was performed in compliance with the guidelines for the Declaration of Helsinki and was approved by medical ethics regulations of the Medical Ethical Committee of Qilu Hospital of Shandong University (Jinan, China).

\section{Diagnostic criteria}

(1) Type 2 diabetes mellitus was defined as fasting plasma glucose $>7 \mathrm{mmol} / \mathrm{l}$, 2-h post-challenge plasma glucose $>11.1 \mathrm{mmol} / \mathrm{l}$, or current use of anti-diabetic drugs, based on the diagnostic criteria set forth by the American Diabetes Association [16].

(2) Hypertension was defined as systolic blood pressure or diastolic blood pressure (SBP/DBP) $\geq 140 / 90$ $\mathrm{mmHg}$ and/or diagnosed hypertension treated with antihypertensive therapy [17].

\section{Clinical and biochemical assessment}

Cardiovascular risk factors and demographic characteristics were obtained from medical records. Cardiovascular risk was assessed in terms of smoking status ( $\geq 20$ packs per year) and alcohol status. BMI was calculated as weight $(\mathrm{kg})$ divided by the square of the height $\left(\mathrm{m}^{2}\right)$. Systolic and diastolic blood pressures were measured using standard methods.

All patients had their blood drawn in the morning after an 8-h fast. Serum was used to analyse low-density lipoprotein cholesterol (LDL-c), total cholesterol (TC), high-density lipoprotein cholesterol (HDL-c), uric acid (UA), triglycerides (TGs) and fasting plasma glucose (FPG) using an automatic biochemistry analyser (Roche Cobas 8000 modular analyser Series C701, Mannheim, Germany). The concentration analysis of cystatin $\mathrm{C}$ was the same as described in a previous paper [11]. eGFR was estimated with the CKD-EPI equation [18]. Von Clauss methods were used to detect fibrinogen, and serum creatinine $(\mathrm{sCr})$ levels were measured using an enzymatic method. Patients with an eGFR $<90 \mathrm{~mL} / \mathrm{min} /$ $1.73 \mathrm{~m}^{2}$ were excluded.

\section{Coronary angiography}

A standard technique was used for coronary angiography. Two experts who were not familiar with the study performed the angiography. Coronary heart disease was diagnosed when angiography showed at least one lesion with lumen stenosis $\geq 50 \%$. The severity of coronary atherosclerosis was based on the Gensini score [19]. Multiple multivessel disease was defined as $>50 \%$ luminal narrowing in the left main coronary artery or in more than three sites of coronary arteries. 


\section{Statistical analysis}

The Kolmogorov-Smirnov test and Levine test were used to evaluate the normality and variance uniformity of the data. The continuous variables with a normal distribution are expressed as the mean \pm standard deviation, and the classification variables are expressed as percentages. Nonnormally distributed variables such as TG and Gensini scores are represented by the median and the quartile range. Chi-square tests were used to compare categorical variables. Normally distributed variables were tested by unpaired Student's t test. Age, BMI, hypertension, sex, smoking status, blood lipids (TC, TGs, LDL-c, HDL-c) and eGFR were identified as potential confounding factors and were adjusted in the model. Spearman correlation analysis was used to determine the factors related to the Gensini score. Logistic regression analysis was used to assess the relationship between cystatin $\mathrm{C}$ and the presence of multivesicular disease. Biomarker cutoff points for multiple vessel disease were analysed by the receiver operating characteristic (ROC) curve. SPSS 16.0 was used to analyse the data (SPSS, Chicago, IL, USA). The significance level was set as a two-tailed $p<0.05$.

\section{Results}

Characteristics of individuals with and without diabetes Among the 135 diabetes and 179 nondiabetic patients who participated in this study, the UA and FPG levels were significantly higher in patients with diabetes than in those without diabetes $(P=0.003, P<0.001$, respectively). There was no difference in age, sex ratio, blood pressure, BMI or lipid profile between the two groups (Table 1). The rates of hypertension and smoking status in patients also showed no difference. Among the patients with CAD, those with diabetes mellitus had significantly higher serum cystatin $\mathrm{C}$ levels than those without diabetes mellitus $(0.75 \pm 0.10$ vs $0.89 \pm 0.11 \mathrm{mg} / \mathrm{L}, P<0.001$; Fig. 1$)$.

\section{Correlation between serum cystatin C and CAD severity}

The relationship between serum cystatin $C$ levels and Gensini score, which represents the extent of multivessel disease, was investigated in the diabetes group (Fig. 2). Spearman correlation analysis showed that serum cystatin C, BMI, fibrinogen and fasting plasma glucose (FPG) were significantly correlated with the Gensini score $(\mathrm{r}=0.306$, $\mathrm{r}=0.217, \mathrm{r}=0.246, \mathrm{r}=0.282, P=0.002, P=0.032 P=0.017$, $P=0.004$, respectively), there was no relationship between HDL-c and the Gensini score $(P=0.162)$ (Table 2).

\section{Diagnostic power of cystatin C for multivessel disease} identified by coronary angiography in type 2 diabetes mellitus patients

Multiple logistic regression analysis was applied to assess the usefulness of cystatin $\mathrm{C}$ as a diagnostic marker for the presence of multivessel disease after adjusting for
Table 1 Clinical and biochemical characteristics of the study subjects

\begin{tabular}{|c|c|c|c|}
\hline & $\begin{array}{l}\text { Non-diabetes } \\
(\boldsymbol{n}=179)\end{array}$ & $\begin{array}{l}\text { Diabetes } \\
(\boldsymbol{n}=135)\end{array}$ & $p$ \\
\hline Age (years) & $54.74 \pm 8.759$ & $56.41 \pm 8.20$ & 0.81 \\
\hline Males\% (n) & $72(129)$ & $65(88)$ & 0.15 \\
\hline smoking\%(n) & $48(86)$ & $48(65)$ & 0.90 \\
\hline Hypertension\%(n) & $63(113)$ & $72(97)$ & 0.25 \\
\hline drinking \%(n) & $48(81)$ & $50(68)$ & 0.66 \\
\hline BMI $\left(\mathbf{k g} / \mathrm{m}^{2}\right)$ & $26.32 \pm 4.42$ & $26.99 \pm 3.06$ & 0.15 \\
\hline Systolic BP (mmHg) & $132.39 \pm 17.93$ & $138.01 \pm 22.69$ & 0.08 \\
\hline Diastolic BP (mmHg) & $78.55 \pm 12.70$ & $80.36 \pm 13.39$ & 0.20 \\
\hline FPG (mmol/L) & $5.27 \pm 1.27$ & $8.39 \pm 2.57$ & $<0.001$ \\
\hline TC (mmol/L) & $4.81 \pm 1.07$ & $4.71 \pm 0.88$ & 0.42 \\
\hline TG (mmol/L) & $1.91 \pm 1.13$ & $2.26 \pm 1.41$ & 0.09 \\
\hline LDL-c (mmol/L) & $2.98 \pm 0.88$ & $2.82 \pm 0.71$ & 0.09 \\
\hline HDL-c (mmol/L) & $1.14 \pm 0.24$ & $1.12 \pm 0.88$ & 0.851 \\
\hline $\mathrm{SCr}(\mu \mathrm{mol} / \mathrm{L})$ & $64.13 \pm 9.97$ & $62.27 \pm 10.18$ & 0.09 \\
\hline eGFR $\left(\mathrm{ml} / \mathrm{min} / 1.73 \mathrm{~m}^{2}\right)$ & $103.11 \pm 7.22$ & $102.83 \pm 7.50$ & 0.72 \\
\hline $\mathrm{UA}(\mu \mathrm{mol} / \mathrm{L})$ & $314.82 \pm 74.65$ & $382.56 \pm 72.67$ & 0.003 \\
\hline Fibrinogen(g/L) & $3.48 \pm 1.12$ & $3.58 \pm 0.81$ & 0.41 \\
\hline Cystatin C (mg/L) & $0.75 \pm 0.10$ & $0.89 \pm 0.11$ & $<0.001$ \\
\hline Gensini score & $16.5 \pm 20.04$ & $41.25 \pm 33.38$ & $<0.05$ \\
\hline
\end{tabular}

$B M I$ body mass index; $B P$ blood pressure; $F P G$ fasting plasma glucose; $T C$ total cholesterol; $T G$ triglyceride; $L D L-c$ low-density lipoprotein cholesterol; $H D L-c$ high-density lipoprotein cholesterol; $\mathrm{SCr}$ serum creatinine; UA uric acid. Data are means \pm SD or median (interquartile range)

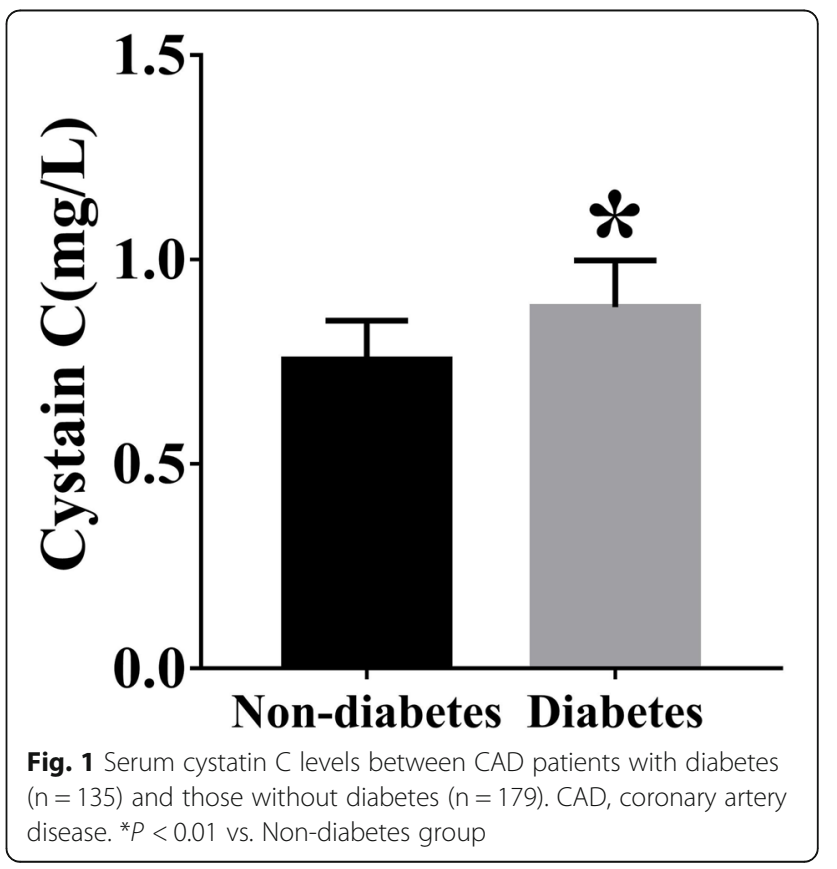




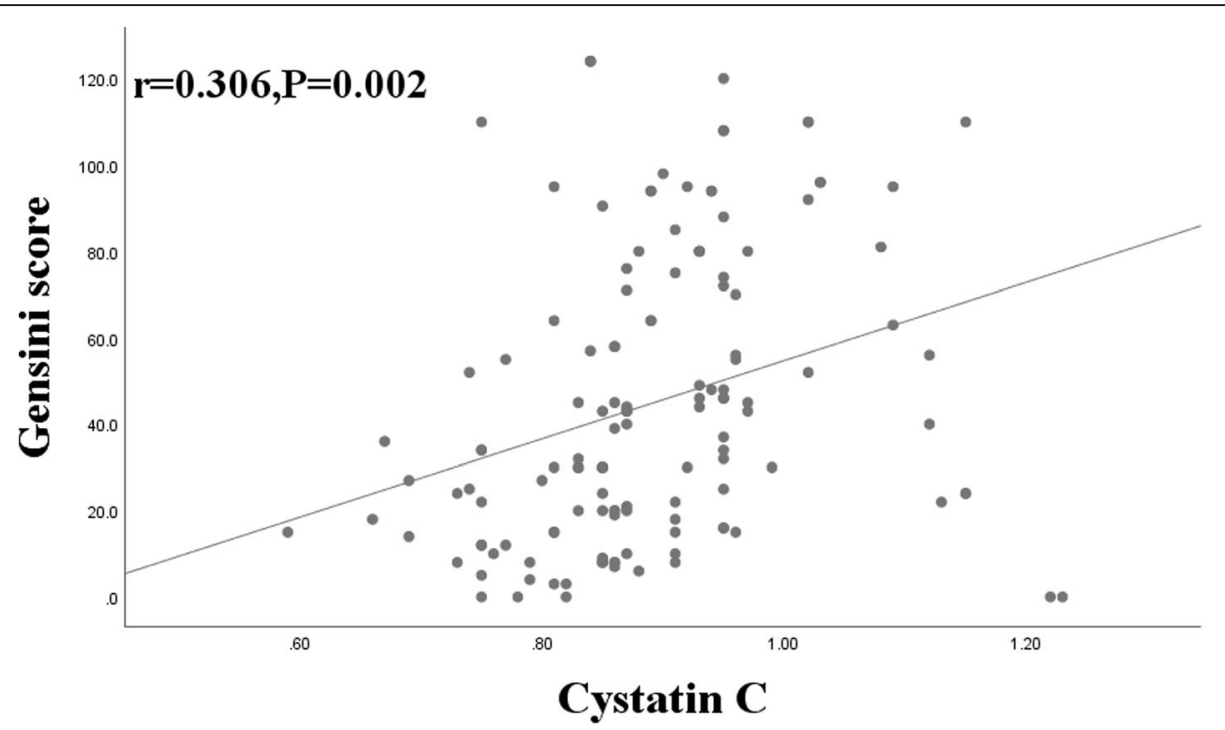

Fig. 2 Correlation between serum cystatin $C$ and the Gensini score, in diabetes mellitus patients with normal renal function. CAD, coronary artery disease

conventional CAD risk factors, including age, sex, BMI, smoking status, hypertension, TC, LDL-c, HDL-c, TGs, SBP, DBP, fibrinogen, SCr, FPG, eGFR and cystatin C. Before Multiple logistic regression analysis, we performed collinearity diagnosis, and the VIF value of all our variables was less than 3.0. Serum cystatin C (odds ratio, $\mathrm{OR}=2.21,95 \%$ confidence interval $(\mathrm{CI})$ : 1.316 $3.727, P=0.003)$ and FPG (OR $=1.28$, 95\% CI: $1.045-$ $1.565, P=0.017)$ were found to be independent predictors of the presence of multivessel disease (Table 3).

The optimal cut-off value for the diagnosis of multivessel disease was determined according to the ROC curves. A serum cystatin $C$ level of $\geq 0.865 \mathrm{mg} / \mathrm{L}$ predicted the presence of multivessel disease with a sensitivity of $67.7 \%$, specificity of $76.3 \%$ and an area under the curve of 0.748 (95\% CI: 0.645-0.851, $P<0.001$, Fig. 3) (Table 4).

\section{Discussion}

In this cross-sectional study, we found a positive relationship between the serum levels of cystatin $\mathrm{C}$ and

Table 2 Correlation of Gensini score with clinical and biological parameters

\begin{tabular}{lll}
\hline Variables & \multicolumn{2}{l}{ Gensini score } \\
\cline { 2 - 3 } & $\mathrm{r}$ & $\mathrm{p}$ \\
\hline Cystatin C (mg/L) & 0.306 & 0.002 \\
BMI (kg/m $\mathbf{2})$ & 0.217 & 0.032 \\
Fibrinogen(g/L) & 0.246 & 0.017 \\
FPG (mmol/L) & 0.282 & 0.004 \\
HDL-c (mmol/L) & 0.055 & 0.162 \\
\hline BMI body mass index; BP blood pressure; $F P G$ fasting plasma glucose; $H D L-c$ &
\end{tabular}

multivessel disease by coronary angiography in type 2 diabetes mellitus patients with normal renal function. Serum cystatin $C$ levels were significantly positively correlated with the Gensini score. In addition, higher serum cystatin $\mathrm{C}$ could independently predict the presence of multivessel disease by coronary angiography. The ability of cystatin $\mathrm{C}$ to distinguish multivessel disease patients among patients with type 2 diabetes mellitus and normal renal function was moderate. Therefore, cystatin $\mathrm{C}$ was a useful biomarker for the identification of multivessel disease in subjects with diabetes mellitus. To the best of our knowledge, this is the first study to demonstrate the usefulness of cystatin $\mathrm{C}$ as a diagnostic tool for multivessel disease and to suggest an optimal cutoff value in diabetes patients with normal renal function.

Serum cystatin $C$ has been shown to be a new risk factor for CAD. Numerous prior studies have suggested that patients with elevated cystatin $\mathrm{C}$ have greater cardiovascular risk and a greater risk of mortality [20-23]. Cystatin $\mathrm{C}$ has been proposed to be not only a sensitive marker of kidney dysfunction but also a biomarker of atherosclerosis and cardiovascular risk. Animal studies have revealed that cystatin $\mathrm{C}$ might interact with the inflammatory response, leading to activation of cathepsins and resulting in the degradation of collagen in the atheroma plaque, leading to an increased risk of rupture [22].

Our results indicate that diabetes patients had higher serum cystatin $C$ levels than nondiabetic patients. This may be explained, at least partly, by the close association of cystatin $\mathrm{C}$ with insulin resistance, obesity and hypertension conditions, which are closely related to diabetes; these associations have been shown in several studies [24-26]. This result is very similar to the report by 
Table 3 Multiple logistic regression analysis indicating factors independently associated with multi-vessel disease in type 2 diabetes mellitus

\begin{tabular}{llllll}
\hline Parameters & $\mathrm{B}$ & $\mathrm{SE}$ & $\mathrm{OR}$ & $95 \% \mathrm{Cl}$ & $\mathrm{P}$ \\
\hline FPG & 0.246 & 0.103 & 1.28 & $1.045-1.565$ & 0.017 \\
Cystatin C & 0.795 & 0.266 & 2.21 & $1.316-3.727$ & 0.003 \\
\hline
\end{tabular}

$B$ regression coefficient; SE standard error; $C l$ confidence interval; $O R$ odds ratio; FPG fasting plasma glucose. Variables included in the model are age, sex, $\mathrm{BMI}$, smoking, alcohol hypertension, and biochemical risk factors TC, LDL-C, HDL-C, TG, SBP, DBP, fibrinogen, SCr, FPG, eGFR and cystatin C

Servais et al. [27], which included 925 dyslipidaemic subjects, including $11 \%$ diabetic patients. HOMA-IR increased in proportion to cystatin $\mathrm{C}$ quartiles and showed an independent association with cystatin $C$ by multiple regression analysis. Because insulin resistance is an important element in the development of type 2 diabetes mellitus, these findings suggest that insulin resistance may play an additional role in the link between cystatin $\mathrm{C}$ and type 2 diabetes mellitus, although the underlying mechanism remains unclear. Recently, K. Sahakyan et al. [28] found an association of serum cystatin $C$ with the incidence of type 2 diabetes mellitus in a long-term population-based study, which further confirmed the close relationship of cystatin $\mathrm{C}$ with diabetes mellitus.

We also found a positive association between serum cystatin $C$ levels and the Gensini score independent of eGFR, even after adjustment for established risk factors associated with cardiovascular disease and cystatin C. Niccoli et al. [29] demonstrated that the independent association between cystatin $C$ and CAD severity was superior to that of creatinine or eGFR, and we obtained similar results. Likewise, Mevlut Koc et al. [30] showed a strong correlation between cystatin $\mathrm{C}$ and the severity of CAD. In this cross-sectional study, cystatin $\mathrm{C}$ was suggested to be a useful laboratory tool in predicting the presence and severity of CAD in daily practice.

Vascular disease that affects macrovasculature is an important cause of morbidity and mortality in diabetic patients. A simple and noninvasive tool for predicting multivessel disease in type 2 diabetes patients is needed. Many studies have been conducted to assess the usefulness of cystatin $C$ in predicting cardiovascular risks and renal dysfunction [31-33], and various cutoff values have been suggested in multiple clinical settings. However, the optimal cutoff value in detecting multivessel disease in patients with type 2 diabetes mellitus and normal renal function has not been suggested to date. We analysed the optimal cut-off value of cystatin $C$ in our study, which indicated an optimal cut-off of $0.865 \mathrm{mg} / \mathrm{L}$ with 67.7 and $76.3 \%$ sensitivity and specificity, respectively. Our results indicated that cystatin $C$ is a stronger predictor of multivessel disease than fasting plasma glucose. Serum cystatin $C$ might be a powerful diagnostic tool to screen for multivessel disease in patients with diabetes mellitus and normal renal function.

Several limitations should be considered when our results are interpreted. First, the sample size of our study was relatively small, and we did not consider medication in our analyses. Second, we did not collect 24-h urine for direct measurements of GFR because of its difficulty in daily practice. However, numerous studies have demonstrated that the creatinine-based eGFR provides a good approximation. Third, given its cross-sectional
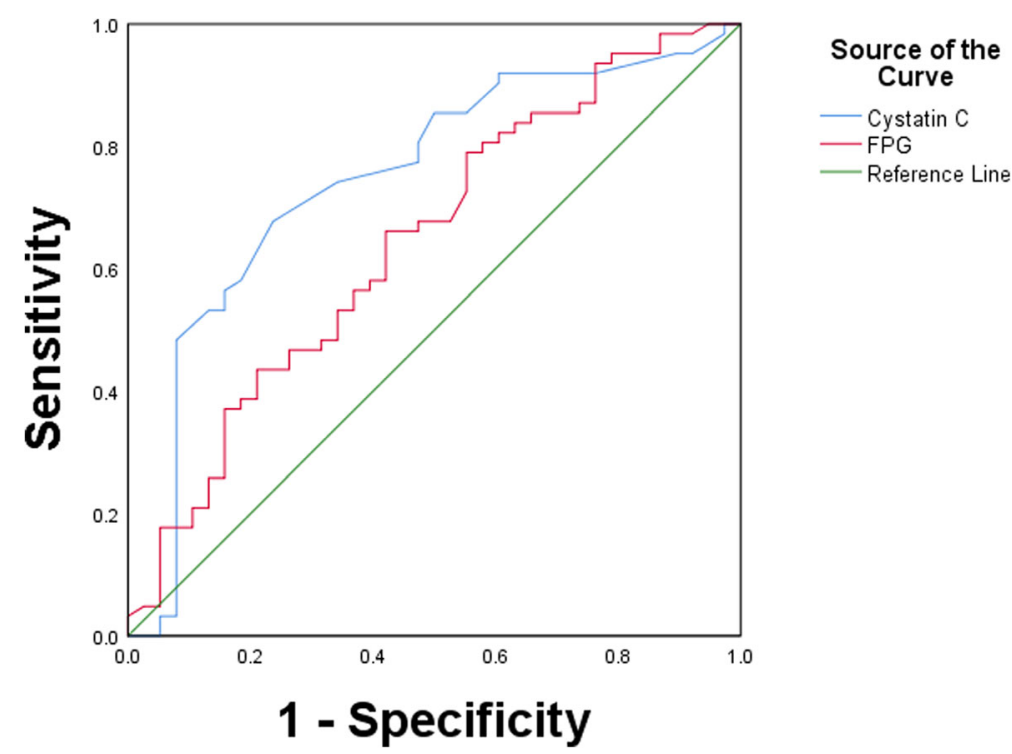

patients with normal renal function. FPG: fasting plasma glucose 
Table 4 Cut-off value, sensitivity, specificity, and area under the curves for biomarkers in predicting for multi-vessel disease in type 2 diabetes mellitus

\begin{tabular}{lllllll}
\hline Biomarkers & Cut-off value & Sensitivity(\%) & Specificity(\%) & AUC & $95 \% \mathrm{Cl}$ & $\mathrm{P}$ \\
\hline FPG (mmol/L) & 6.740 & 79.0 & 44.7 & 0.644 & $0.531-0.756$ \\
Cystatin C (mg/L) & 0.865 & 67.7 & 76.3 & 0.748 & $0.645-0.851$ & 0.016 \\
\hline
\end{tabular}

FPG fasting plasma glucose; $C l$ confidence interval; $A U C$ area under curve

design, a causal relationship between cystatin $C$ indices and multivessel disease prevalence cannot be inferred.

\section{Conclusion}

In summary, our findings demonstrate that cystatin $C$ was significantly associated with the severity of CAD and independently predicted the presence of multivessel disease in patients with diabetes mellitus with normal renal function. Cystatin $\mathrm{C}$ emerged as a potential marker for identifying multivessel disease in populations that may benefit from therapeutic strategies aimed at preventing the development of multivessel coronary artery disease. Further research is warranted to clarify the pathophysiologic mechanisms responsible for these associations.

\section{Abbreviations}

CAD: Cardiovascular diseases; eGFR: Estimating glomerular filtration rate; DM: Diabetes mellitus; SBP: Systolic blood pressure; DBP: Diastolic blood pressure; BMI: Body mass index; HOMA-IR: Homeostasis model assessment of insulin resistance

\section{Acknowledgements}

Not Applicable.

\section{Authors' contributions}

QX participated in the design of the study, SW and XZ performed the statistical analysis, SW and JS drafted the manuscript. SW and FG contributed to the acquisition of data and its interpretation. QX and QL conceived of the study. All authors read and approved the manuscript.

\section{Funding}

This study was supported by National Natural Science Foundation of China (81170794, 81572191), Shandong Provincial Natural Science Foundation, China (2019GSF108029). And these funding bodies played no role in the design of the study and collection, analysis, and interpretation of data and in writing the manuscript.

\section{Availability of data and materials}

All data generated or analysed during this study are included in this published article and its additional information fles.

\section{Ethics approval and consent to participate}

Written informed consent was obtained from all subjects. The study was performed in compliance with the guidelines for the Declaration of Helsinki and was approved by medical ethics regulations of the Medical Ethical Committee of Qilu Hospital of Shandong University (Jinan, China).

\section{Consent for publication}

All authors agree to publication, and there are no permissions needed.

\section{Competing interests}

The authors declare that they have no competing interests.

\section{Author details}

'Department of Orthopedics, Qilu Hospital of Shandong University, Jinan, China. ${ }^{2}$ School of Medicine, Shandong University, Jinan, China. ${ }^{3}$ Pharmacy Department, Qilu Hospital of Shandong University, No.107, Wen Hua Xi Road,
Jinan, Shandong 250012, People's Republic of China. ${ }^{4}$ Shandong Provincial Qianfoshan Hospital, Jinan, China.

Received: 1 February 2020 Accepted: 12 April 2020

Published online: 19 April 2020

\section{References}

1. Geiss LS, Pan L, Cadwell B, Gregg EW, Benjamin SM, Engelgau MM. Changes in incidence of diabetes in U.S. adults, 1997-2003. Am J Prevent Med. 2006; 30(5):371-7.

2. Laakso M, Kuusisto J. Insulin resistance and hyperglycaemia in cardiovascular disease development. Nat Rev Endocrinol. 2014;10(5):293-302.

3. Buse JB, Ginsberg HN, Bakris GL, Clark NG, Costa F, Eckel R, Fonseca V, Gerstein HC, Grundy S, Nesto RW, et al. Primary prevention of cardiovascular diseases in people with diabetes mellitus: a scientific statement from the American Heart Association and the American Diabetes Association. Circulation. 2007;115(1):114-26.

4. Berry C, Tardif JC, Bourassa MG. Coronary heart disease in patients with diabetes: part I: recent advances in prevention and noninvasive management. J Am Coll Cardiol. 2007;49(6):631-42.

5. Wei M, Gaskill SP, Haffner SM, Stern MP. Effects of diabetes and level of glycemia on all-cause and cardiovascular mortality. The San Antonio heart study. Diabetes Care. 1998;21(7):1167-72.

6. Inker LA, Schmid CH, Tighiouart H, Eckfeldt JH, Feldman HI, Greene T, Kusek $J W$, Manzi J, Van Lente F, Zhang YL, et al. Estimating glomerular filtration rate from serum creatinine and cystatin C. N Engl J Med. 2012;367(1):20-9.

7. Filler G, Bokenkamp A, Hofmann W, Le BT, Martinez-Bru C, Grubb A. Cystatin $\mathrm{C}$ as a marker of GFR--history, indications, and future research. Clin Biochem. 2005;38(1):1-8.

8. Hsiao PG, Hsieh CA, Yeh CF, Wu HH, Shiu TF, Chen YC, Chu PH: Early prediction of acute kidney injury in patients with acute myocardial injury. Journal of critical care 2012, 27(5):525.e521-527.

9. Sarnak MJ, Katz R, Stehman-Breen CO, Fried LF, Jenny NS, Psaty BM, Newman AB, Siscovick D, Shlipak MG. Cystatin C concentration as a risk factor for heart failure in older adults. Ann Intern Med. 2005;142(7):497-505.

10. Hoke M, Pernicka E, Niessner A, Goliasch G, Amighi J, Koppensteiner R, Minar E, Mlekusch W, Rumpold H, Wagner O, et al. Renal function and longterm mortality in patients with asymptomatic carotid atherosclerosis. Thromb Haemost. 2012;107(1):150-7.

11. Qing X, Furong W, Yunxia L, Jian Z, Xuping W, Ling G. Cystatin C and asymptomatic coronary artery disease in patients with metabolic syndrome and normal glomerular filtration rate. Cardiovasc Diabetol. 2012;11:108.

12. Surendar J, Indulekha K, Aravindhan V, Ganesan A, Mohan V. Association of cystatin-C with metabolic syndrome in normal glucose-tolerant subjects (CURES-97). Diabetes Technol Ther. 2010;12(11):907-12.

13. Bokenkamp A, van Wijk JA, Lentze MJ, Stoffel-Wagner B. Effect of corticosteroid therapy on serum cystatin $C$ and beta2-microglobulin concentrations. Clin Chem. 2002;48(7):1123-6.

14. Knight EL, Verhave JC, Spiegelman D, Hillege HL, de Zeeuw D, Curhan GC, de Jong PE. Factors influencing serum cystatin $C$ levels other than renal function and the impact on renal function measurement. Kidney Int. 2004; 65(4):1416-21.

15. Fricker M, Wiesli P, Brandle M, Schwegler B, Schmid C. Impact of thyroid dysfunction on serum cystatin C. Kidney Int. 2003;63(5):1944-7.

16. Diagnosis and classification of diabetes mellitus. Diabetes care 2008, 31 Suppl 1:S55-60.

17. National High Blood Pressure Education P. In: The Seventh Report of the Joint National Committee on Prevention, Detection, Evaluation, and Treatment of High Blood Pressure. edn. Bethesda (MD): National Heart, Lung, and Blood Institute (US); 2004.

18. $A S L, J C, H T, T G, L a$ I. Measured and estimated glomerular filtration rate: current status and future directions. Nat Rev Nephrol. 2020;16(1):51-64. 
19. Gensini GG. A more meaningful scoring system for determining the severity of coronary heart disease. Am J Cardiol. 1983;51(3):606.

20. Ichimoto E, Jo K, Kobayashi Y, Inoue T, Nakamura Y, Kuroda N, Miyazaki A, Komuro I. Prognostic significance of cystatin C in patients with ST-elevation myocardial infarction. Circulation J. 2009;73(9):1669-73.

21. Silva D, Cortez-Dias N, Jorge C, Marques JS, Carrilho-Ferreira P, Magalhaes A, Martins SR, Goncalves S, da Silva PC, Fiuza M, et al. Cystatin C as prognostic biomarker in ST-segment elevation acute myocardial infarction. Am J Cardiol. 2012;109(10):1431-8.

22. Ge C, Ren F, Lu S, Ji F, Chen X, Wu X. Clinical prognostic significance of plasma cystatin $\mathrm{C}$ levels among patients with acute coronary syndrome. Clin Cardiol. 2009;32(11):644-8.

23. Lassus J, Harjola VP, Sund R, Siirila-Waris K, Melin J, Peuhkurinen K, Pulkki K Nieminen MS. Prognostic value of cystatin $C$ in acute heart failure in relation to other markers of renal function and NT-proBNP. Eur Heart J. 2007;28(15):1841-7.

24. Retnakaran R, Connelly PW, Harris SB, Zinman B, Hanley AJ: Cystatin C is associated with cardiovascular risk factors and metabolic syndrome in Aboriginal youth. Pediatric nephrology (Berlin, Germany) 2007, 22(7):10071013.

25. Demircan N, Gurel A, Armutcu F, Unalacak M, Aktunc E, Atmaca H: The evaluation of serum cystatin $\mathrm{C}$, malondialdehyde, and total antioxidant status in patients with metabolic syndrome. Medical science monitor : international medical journal of experimental and clinical research 2008 14(2):Cr97-101.

26. Vigil L, Lopez M, Condes E, Varela M, Lorence D, Garcia-Carretero R, Ruiz J. Cystatin $C$ is associated with the metabolic syndrome and other cardiovascular risk factors in a hypertensive population. JASH. 2009;3(3):2019

27. Servais $A$, Giral $P$, Bernard $M$, Bruckert E, Deray $G$, Isnard Bagnis $C$. Is serum cystatin-C a reliable marker for metabolic syndrome? Am J Med. 2008; 121(5):426-32.

28. Sahakyan K, Lee KE, Shankar A, Klein R. Serum cystatin C and the incidence of type 2 diabetes mellitus. Diabetologia. 2011;54(6):1335-40.

29. Niccoli G, Conte M, Della Bona R, Altamura L, Siviglia M, Dato I, Ferrante G, Leone AM, Porto I, Burzotta F, et al. Cystatin C is associated with an increased coronary atherosclerotic burden and a stable plaque phenotype in patients with ischemic heart disease and normal glomerular filtration rate. Atherosclerosis. 2008;198(2):373-80.

30. Koc M, Batur MK, Karaarslan O, Abali G. Clinical utility of serum cystatin C in predicting coronary artery disease. Cardiol J. 2010;17(4):374-80.

31. Ahlstrom A, Tallgren M, Peltonen S, Pettila V. Evolution and predictive power of serum cystatin C in acute renal failure. Clin Nephrol. 2004;62(5): $344-50$

32. Beauvieux MC, Le Moigne F, Lasseur C, Raffaitin C, Perlemoine C, Barthe N Chauveau P, Combe C, Gin H, Rigalleau V. New predictive equations improve monitoring of kidney function in patients with diabetes. Diabetes Care. 2007:30(8):1988-94.

33. Krawczeski CD, Vandevoorde RG, Kathman T, Bennett MR, Woo JG, Wang Y, Griffiths RE, Devarajan P. Serum cystatin C is an early predictive biomarker of acute kidney injury after pediatric cardiopulmonary bypass. CJASN. 2010 5(9):1552-7.

\section{Publisher's Note}

Springer Nature remains neutral with regard to jurisdictional claims in published maps and institutional affiliations.

Ready to submit your research? Choose BMC and benefit from:

- fast, convenient online submission

- thorough peer review by experienced researchers in your field

- rapid publication on acceptance

- support for research data, including large and complex data types

- gold Open Access which fosters wider collaboration and increased citations

- maximum visibility for your research: over $100 \mathrm{M}$ website views per year

At $\mathrm{BMC}$, research is always in progress.

Learn more biomedcentral.com/submissions 